Língua e Literatura, n. 20, p. 63-79, 1992/1993.

\title{
A ENTOAÇÃO E A ORGANIZAÇÃO EM TÓPICO-COMENTÁRIO EM ENUNCIADOS INTERROGATIVOS
}

\author{
Norma Hochgreb*
}

RESUMO: O objetivo do presente trabalho é examinar o papel da entoação na expressão da organização em tópico-comentário em enunciados interrogativos do português. Analisando questões totais e parciais submetidas previamente a um tratamento instrumental, procura-se identificar os padrões entoativos básicos associados à organização enunciativa em T-C e verificar de que forma esses padrōes se relacionam com as diversas estruturas sintáticas observadas.

No nível do enunciado reconhece-se normalmente uma organização da informação em duas partes básicas, que chamaremos de tópico (T) e comentário (C). O tópico é a parte do enunciado tratada pelo locutor como elemento não informativo e que serve de suporte para a informação nova; o comentário é a parte do enunciado tratada pelo locutor como informativa, constituindo o elemento essencial da comunicação. Nos enunciados interrogativos, o comentário constitui o objeto da questão; trata-se do constituinte assumido pelo locutor como conhecido do ouvinte, mas não dele, locutor.

A organização em T-C nos enunciados abaixo seria normalmente a seguinte:

1. Os meninos já chegaram?

$\mathrm{T} \quad \mathrm{C}$

2. Seus pais, onde trabalham?

$\mathrm{T} \quad \mathrm{C}$

3. Vamos sair, quando a chuva parar?

C $\mathrm{T}$

4. Tudo bem, na sua casa?

C T

O comentário é naturalmente o elemento obrigatório da questão. O tópico, porém, é freqüentemente omitido:

(*) Professora da Universidade de São Paulo. 


\section{Quer café ?}

C

\section{6. $\underline{\text { O que está acontecendo ? }}$}

\section{C}

Em enunciados elípticos, pode aparecer só o tópico. Nesse caso, o objeto da questão (o comentário) não é formulado, ficando subentendido pelo contexto ou pela situação:

\section{E no dia seguinte? \\ $\mathrm{T}$ \\ 8. EMaria? \\ $\mathrm{T}$}

Para Danees $(60,67)$ o tópico é a coisa conhecida e sobre a qual se fala, enquanto o comentário é a informação nova - o que é dito sobre o tópico. As noções de "já conhecido" e de "ainda não conhecido" dizem respeito ao contexto e à situação, que determinam em grande parte a probabilidade de um elemento ser o tópico ou o comentário do enunciado. Isso porém nem sempre acontece. Como acentua Perrot, "rien n'impose que le déjà connu fournisse le thème, le non encore connu le rhème : il appartient à la stratégie du locuteur d'en décider. Mais si une situation crée ainsi une probabilité plus ou moins forte en faveur d'une certaine organisation du message, il est toujours possible au locuteur d'adopter une autre stratégie que celle que ferait attendre la situation. Il peut par exemple, reprendre comme rhème, dans une argumentation, un élément déjà acquis" (Perrot, 1967, pg. 92)

$\mathrm{Na}$ verdade, pode haver informações novas tanto no tópico quanto no comentário. Mas as estratégias discursivas permitem ao locutor estabelecer uma hierarquia no aporte de informações. Assim, o tópico constituirá a parte do enunciado tratada como menos informativa (e como base para novas informações) enquanto o comentário será tratado como a parte mais informativa, constituindo a parte importante da mensagem.

Um exame mais atento nos faz ver, entretanto, que a distinção em tópicocomentário não é sempre suficiente para dar conta da organização da informação na mensagem. Consideremos o enunciado:

\section{No sul do país, faz muito frio?}

\section{$\mathrm{T}$}

Dentro dessa organização básica (mas não obrigatória), o locutor pode pôr em relevo (normalmente através da entoação) um ou mais constituintes, tanto no interior do tópico quanto no interior do comentário. 
Poderíamos ter, por exemplo:

\section{No sul do país, faz muito frio ? \\ $\mathrm{T}$ \\ C}

Aí, sul e muito são focalizados.

Da mesma forma, podemos reconhecer dois níveis de estruturação enunciativa na frase seguinte:

\section{E os outros amigos, onde foram? $\mathrm{T}$

Este tipo de relevo tem sido descrito sob denominações diferentes. Tradicionalmente o termo utilizado é "acento de insistência ", já encontrado em Marouzeau (1924), que distingue o acento de insistência intelectual do afetivo. Danes (1967) considera essa forma de relevo como ênfase contrastiva, marcando que uma palavra contrasta com outra (sub-entendida ou previamente expressa) ou que uma palavra introduz uma idéia nova e inesperada. Em artigo de 1952, Bolinger chama essas realizações de "sentences of the second instance", sugerindo um segundo nível de organização.

Conforme se nota nos exemplos acima, essa forma de realce não coincide sempre com o comentário, mas marca, facultativamente, o elemento mais importante da informação, tanto no interior do comentário quanto no interior do tópico.

A percepção de que se pode ter aí dois níveis de organização do aporte de informação se encontra de modo explícito em autores como Zwanenburg, Halliday e Rossi que, pesquisando em linhas diferentes, propõem modelos de descrição que levam em conta a complexidade desses fatos.

Zwanenburg (1965), por exemplo, descreve a entoação do francês em duas etapas, ou duas organizações em "thème" e "propos" : a primeira, que corresponde aos contornos entoativos finais de segmentos sintáticos, e a segunda, que corresponde aos contornos interiores de segmentos sintáticos, ou seja, ao relevo de itens lexicais dentro do "thème" ou do "propos"

O modelo de Halliday (1976), por outro lado, considera a estrutura temática em tema-rema e a estatura informativa em dado-novo como dois aspectos distintos da organização textual, ainda que estritamente ligados entre si. Analisando o enunciado : "This gazebo / can't have been built by Wren" Halliday considera "This gazebo" como o tema e "can't have been built by Wren " como o rema; por outro lado, this e can't são elementos novos, que se opõem a "gazebo" $e$ "have been built by Wren" elementos dados. (Halliday, 1976, pg. 156). Embora Halliday prefira considerar as duas estruturas separadamente, julgamos que elas poderiam ser vistas como níveis diferentes de uma organização mais complexa. 
Na colocação de Rossi e Di Cristo, é a própria estrutura em tema-rema que é abordada em níveis diferentes. Num modelo bastante complexo de detecção automática das fronteiras entoativas e sintáticas do francês, os autores propõem uma série de regras gerativas de enunciação, onde se estabelecem temas e remas de nível 1, de nível 2, etc. (Rossi e Di Cristo, 1980, pg. 220)

Nas concepções acima, evidencia-se um esforço no sentido de dar conta, de um lado, da estrutura em tópico-comentário e , de outro lado, do relevo de unidades lexicais que se situam no interior dessa estrutura. Parece-nos que a adoção de um modelo de níveis diferentes permite uma descrição mais satisfatória da estrutura enunciativa; o maior interesse de um modelo desse tipo é que possibilita incluir fatos que são por vezes considerados sob a denominação imprecisa de acento de insistência ou enfático mas que, na realidade, dizem respeito à mesma ordem de fenômenos que a organização em T-C.

Dentro dessa perspectiva, optamos por um modelo de análise que compreende dois níveis de estruturação. Num primeiro nível situamos a distinção entre tópico e comentário, que corresponde à oposição tradicional entre sujeito e predicado psicológicos. Quando demarcados pela entoação, esses constituintes formam grupos prosódicos com características próprias, que analisaremos posteriormente do ponto de vista acústico-perceptivo. Num segundo nível situamos os casos de focalização de constituintes no interior do tópico ou do comentário. Tais núcleos informativos serão chamados de "focos" embora não haja sempre coincidência entre essa noção e o "foco" na concepção de Chomsky.

Consideremos agora o papel que assume a entoação entre os meios lingüísticos utilizados na estruturação enunciativa, no nível do enunciado. Numa estrutura não marcada, o tópico corresponde ao sujeito gramatical, enquanto o comentário corresponde ao predicado gramatical. Teríamos então:

\section{Paulo trouxe os discos. suj.-T pred.-C}

Aí, a entoação é redundante como marca enunciativa, já que a organização em T-C é expressa pela própria sintaxe. Seu papel torna-se mais efetivo ao marcar uma organização diferente da que é dada pela sintaxe. Tomemos o enunciado interrogativo "12. Seu filho leu esse livro? "em que a estrutura T-C não marcada seria:

\section{2. a) Seu filho leu esse livro? $\mathrm{T}$ $\mathrm{C}$}

Dependendo das necessidades de enunciação, o locutor pode preferir outras formas de organização, mantendo a mesma estrutura sintático-semântica de base: 
12. b) Foi esse livro que seu filho leu?

C $\mathrm{T}$

12. c) Esse livro, seu filho leu? C $T$

12. d) Seu filho leu esse livro? $T \quad T$

12. e) Seu filho leu esse livro? C $\mathrm{T}$

Em português, como em línguas tipologicamente semelhantes, são utilizados três tipos de procedimentos para marcar o aporte de informação:

1) sintáticos - emprego de construções do tipo : "ser...que (m)";

2) táticos - alteração na ordem normal dos constituintes;

3) entoativos.

Há freqüentemente combinação de marcas diferentes para obtenção do mesmo efeito. Por exemplo, em 12.b) e em 12.c) verificam-se contornos entoativos específicos tanto para o tópico quanto para o comentário, embora a estrutura já seja marcada pela sintaxe ou pela ordem dos constituintes.

Entre os procedimentos citados a entoação assume um papel privilegiado e sua participação é constante, ora como marca ûnica, ora como marca complementar. A organização em T-C, bem como a focalização dos núcleos informativos são sempre expressas pela entoação, ainda que se observem outros procedimentos de relevo.

\section{Análise}

Examinaremos a seguir, a partir da análise de frases interrogativas de vários tipos, de que forma as unidades entoativas se combinam na expressão da estrutura enunciativa e procuraremos estabelecer algumas correlações entre essa estruturação prosódica e a sintaxe do enunciado.

\subsection{Padrões entoativos básicos}

Utilizaremos como instrumentos de análise dez padrões entoativos das frases interrogativas do português, que foram definidos em trabalho anterior ${ }^{1}$ Esses padrões, associados a grupos prosódicos, serviram sobretudo como índices de referência, facilitando a interpretação e sistematização dos resultados. Estão agrupados em três tipos principais:

(1) Hochgreb, N. (1983) págs. 60-86. Esses padrões foram determinados a partir da análise acústico-perceptiva de 400 realizações de frases interrogativas. 
Padrões continuativos:

ct.asc. 1

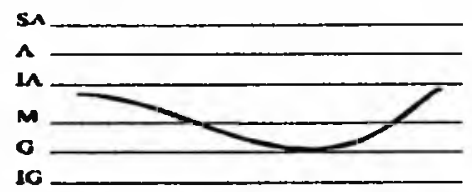

ct.asc. 2

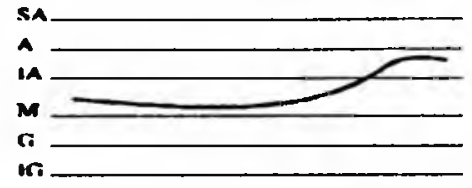

ct.niv.

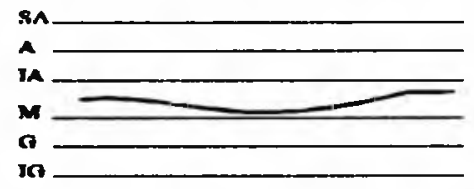

Padrões terminais:

tm.asc. 1

(a ou b)

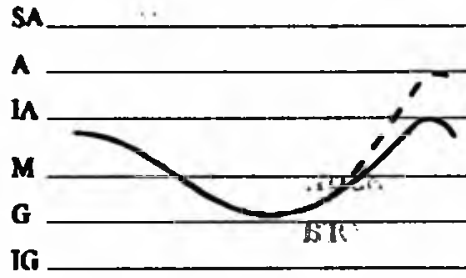

tm.asc. 2 sA

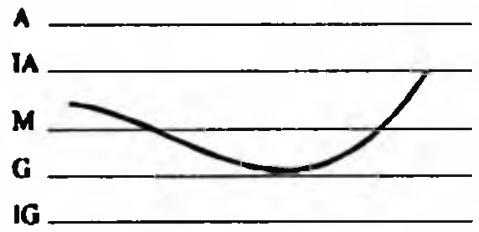

ct.desc. I

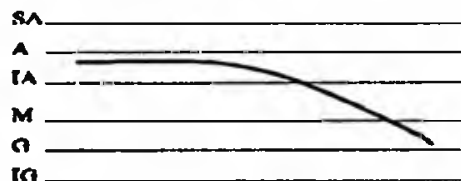

ct.desc. 2

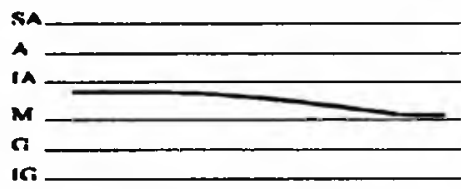

tm.desc. 1

(a ou b)

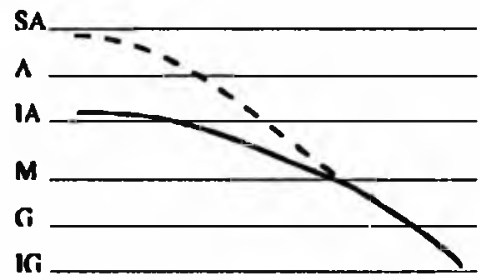

tm.desc. 2

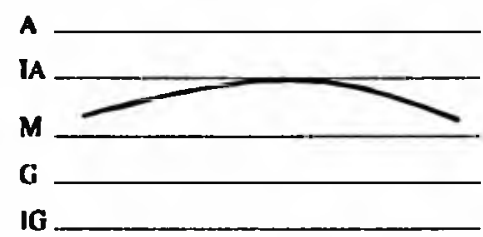

Padrōes parentéticos:

par.gr.

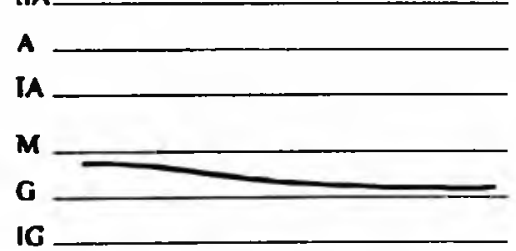

ct: continuativo desc: descendente gr: grave asc: ascendente

par: parentético tm: terminal

niv: nivelado 


\subsection{Configurações entoativas}

As frases examinadas foram submetidas inicialmente a uma análise acústico-perceptiva pluriparamétrica, compreendendo medidas de altura tonal, duração e intensidade. Esses dados, levantados para cada grupo prosódico, foram em seguida confrontados com os parâmetros médios dos padrões apresentados acima, o que permitiu a identificação das configurações entoativas características. ${ }^{2}$

Observaremos sucessivamente os seguintes casos:

- estruturas enunciativas não marcadas;

- estruturas enunciativas marcadas por procedimentos táticos e sintáticos;

- estruturas enunciativas marcadas apenas pela entoação.

\subsection{Estruturas não marcadas}

Questões totais:

Nesse caso há coincidência entre tópico e sujeito gramatical e entre comentário e predicado gramatical.

Exemplos:

13. "As crianças já chegaram?"

$\mathrm{T} \quad \mathrm{C}$

14. "Os arranjos são dele?"

$T$

C

15. "Quer café? "

$\mathrm{C}$

16. "Esse apartamento é do seu amigo que está no Rio?"

$\mathrm{T}$

C

A entoação tende aí a revelar a estrutura sintática, demarcando as fronteiras entre os constituintes básicos : S-P.

A configuração mais comum é a seguinte:

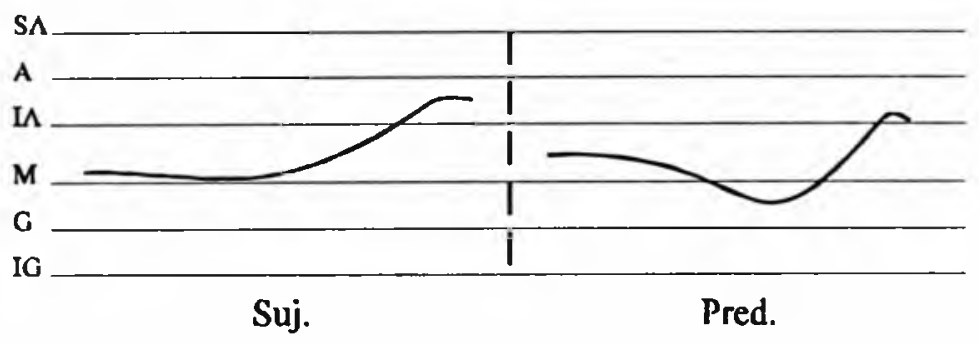

T-ct.asc. 2 C-tm.asc. 2

(2) Para maiores detalhes quanto aos procedimentos instrumentais, cf. Hochgreb, N. (1983) 


\section{Observações:}

a) A demarcação prosódica entre o sujeito e o predicado não é constante. Dependendo da escolha do falante, o mesmo enunciado pode apresentar ou não fronteira prosódica entre esses constituintes.

b) Quando o sujeito é pronome clítico, não se verifica normalmente fronteira prosódica entre sujeito e predicado.

c) Quando o constituinte ( $\mathrm{S}$ ou $\mathrm{P}$ ) é longo, pode haver cisão em grupos secundários.

\section{Questões parciais}

Não havendo nenhuma marca específica (sintática, tática ou entoativa) de organização enunciativa, toda a questão constitui o comentário.

Exemplos:

\section{Como?}

$\mathrm{C}$

18. O que estamos esperando?

C

19. Quantos pães ainda sobraram?

C

O núcleo do comentário (e, naturalmente, o núcleo da questão) é o constituinte representado pelo pronome interrogativo. Pode-se dizer que constitui o foco do enunciado, situando-se num segundo nível de organização. É preciso deixar claro, porém, que a focalização desse elemento faz parte de uma estrutura sentida como neutra, não marcada; não se trata, nesse caso, de ênfase contrastiva.

O padrão característico desse enunciados é o term.desc.1, embora também possa ocorrer um padrão complexo com final ascendente.

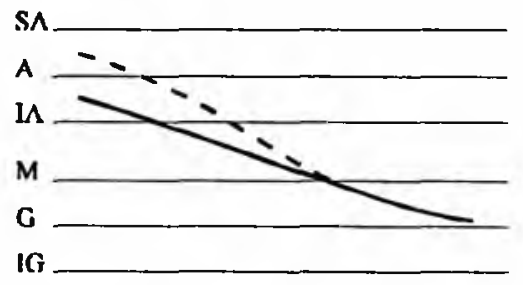

Quando o enunciado é mais longo, pode haver cisão em grupos prosódicos secundários. Nesse caso, a fronteira entoativa corresponde à delimitação sintática. É o que ocorre em: 
A fronteira prosódica entre esses grupos secundários é em geral fraca, sendo marcada sobretudo pela maior duração da tônica. Mas a formação desses sub-grupos não altera a configuração melódica do comentário que, no conjunto, corresponde ao padrão term.desc. 1 .

\subsection{Estrutura enunciativa marcada por procedimentos táticos e sintáticos}

\subsubsection{Mudança na ordem dos constituintes}

Algumas alterações nessa ordem podem ser feitas sem implicar necessariamente em marca enunciativa. Por exemplo, nas questões parciais, a inversão do sujeito é muitas vezes sentida como não marcada, com em 21 e 22 :

21. Como vai você?

22. Como funciona esse aparelho?

Não obstante, a mudança na ordem é usada freqüentemente como procedimento enunciativo, permitindo uma hierarquização diferente no aporte da informação. Examinaremos alguns desses casos.

\section{a) Anteposição do Predicado}

Nas interrogativas totais, a anteposição do predicado corresponde a um relevo do comentário, que passa a ocupar a posição inicial da frase:

\section{Já acabaram as frutas que eu comprei?}

C $T$

24. Foi bom ofilme de ontem?

C $\mathrm{T}$

No nível suprassegmental, a anteposição do predicado é marcada por um padrão terminal característico das interrogativas totais. Nesse caso, tanto o comentário curanto o tópico são normalmente afetados pelo mesmo padrão entoativo term.asc.l (a ou b)

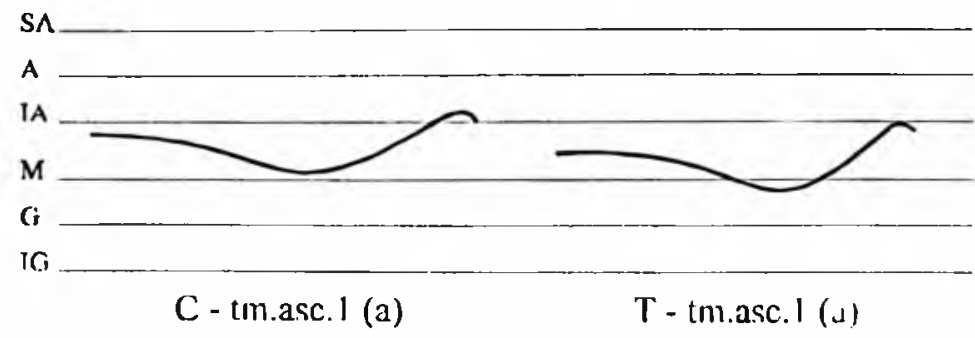




\section{b) Anteposição do circunstante ou do sujeito}

Quando acompanhada de segmentação entoativa, a anteposição desses constituintes implica em topicalização, isto é, em realce do tópico.

A anteposição do sujeito só constitui marca enunciativa nas interrogativas parciais, onde representa um desvio em relação à ordem normal. A anteposição do circunstante, porém, ocorre igualmente nas questões totais e parciais, tratadas aqui conjuntamente, já que os padrões entoativos utilizados para a topicalização são os mesmos nos dois tipos de enunciado. Exemplos:

25. E nós, quando vamos embora?

26. E pra você, o que é que acontece?

27. No final do estágio, você se sente mais preparado?

Aqui, interessa-nos examinar os padrões ligados à manifestação do tópico, pois a entoação do comentário será determinada pelo padrão termina’ característico da modalidade do enunciado.

Nas realizações desse tipo, encontramos dois padrões distintos:

1. padrão ct. asc.1

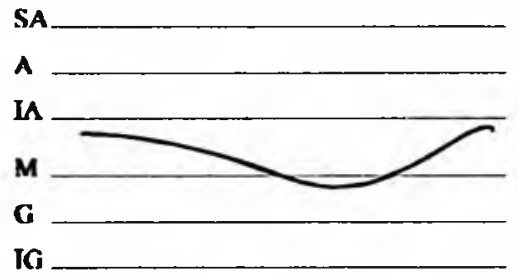

2. padrão ct. desc. 1

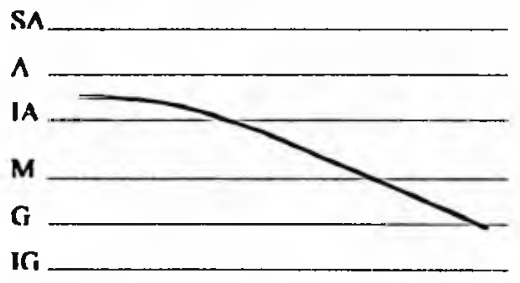

Os dois padrōes parecem poder alternar-se em alguns contextos. No entanto, os sintagmas mais longos mostram-se mais facilmente afetados pelo tipo ascendente. Por outro lado, a entoação descendente marca o tópico de modo mais enfático.

No caso das questões elípticas temáticas, em que apenas o tópico é expresso, o padrão mais freqüente também é o ct.desc.1. Exemplos:

28. E daí?

29. E na sua cidade?

c) Posposição do vocábulo interrogativo (ou do constituinte que o contém)

Nas interrogativas parciais ocorre freqüentemente o deslocamento do vocábulo interrogativo, que constitui o foco da questão. Esse procedimento pode acarretar um relevo suplementar do foco, mas isso não ocorre necessariamente. Em alguns casos, a posposição parece determinar apenas uma variante socio-lingüística de nível mais informal: 
30. Essa peça entra quando em cartaz?

31. Ele ganhou quantos livros?

32. Você nāo trabalha por quê?

Nesse caso, a seqüência que precede o foco situa-se entre os níveis médio e agudo, o contorno é de tipo descendente (M-G) e a seqüência que segue o foco situa-se sempre no nivel grave ou infra-grave:

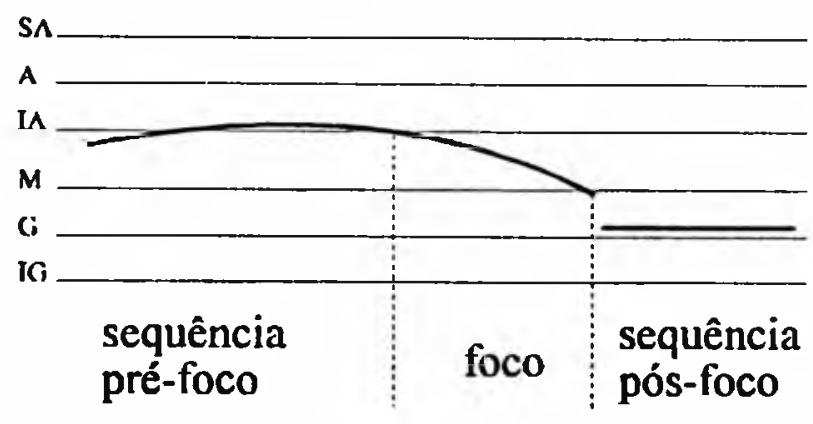

\subsubsection{Procedimentos sintáticos de relevo}

\section{Interrogativas totais}

Através de uma estrutura sintática do tipo "ser...que (m)", um dos constituintes é enfatizado como comentário. Há, simultaneamente, um deslocamento do elemento marcado para o início do enunciado. Exemplos:

33. É amanhã que você viaja?

34. É por causa do frio que suas mãos tremem?

A marca sintática vem normalmente reforçada por marca entoativa. A configuração entoativa característica é:

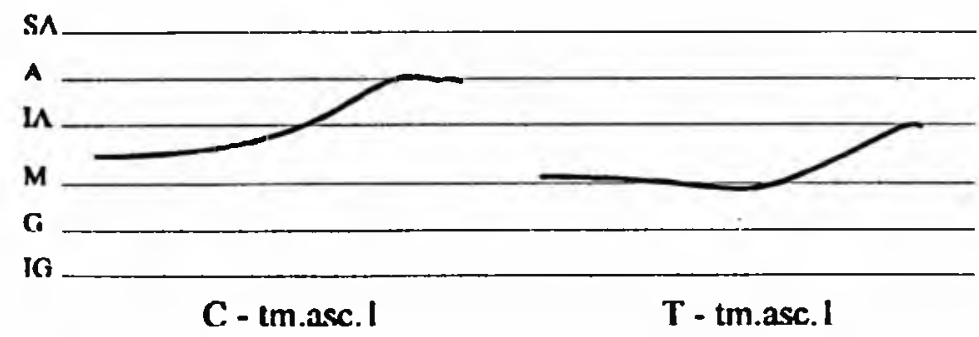

A estrutura entoativa desse tipo de enunciado é semelhante à descrita em 2.2.1., quando há anteposiçāo do predicado. Em ambos os casos, temos o padrão ter.asc. 1 no comentário e no tópico. Observa-se, porém, que o nível tonal do contorno é nitidamente mais elevado no $1 \mathrm{GP}$. 
Interrogativas parciais:

As construções do tipo "o que é que" "por que é que" não constituem sempre estruturas marcadas do ponto de vista enunciativo. Não havendo ênfase pela entoação, essas formas são simples variantes sociolingüísticas, correspondendo a um registro informal:

35. Onde é que ele está?

36. Como é que seus pais ficaram sabendo?

Nos enunciados examinados, encontramos realizações mais ou menos enfatizadas. No enunciado seguinte, observa-se também uma variação do pico tonal, conforme o informante:

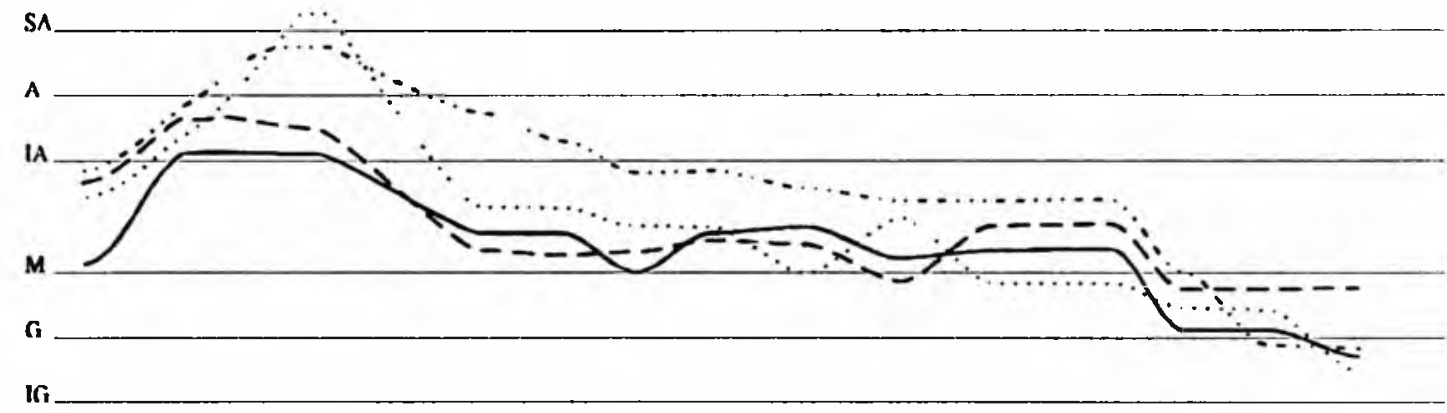

36.a. E quanto é que você coloca de gasolina?

\subsubsection{Estrutura marcada apenas pela entoação}

Nos casos que analisamos a seguir, a entoação marca sozinha a estrutura enunciativa, contrariando as indicaçōes dadas pela sintaxe.

2.2.3.1. Num primeiro nível de estruturação, a entoação segmenta o enunciado em dois GPs principais, (T-C), numa organização diferente da que seria prevista sintaticamente.

\section{Interrogativas totais}

Consideremos o seguinte enunciado:

37. No dia seguinte, ele saiu?

A estrutura prevista sintaticamente é T-C ( = quero saber se ele saiu) mas a entoação pode imprimir ao enunciado a estrutura C-T ( = quero saber se foi no dia seguinte que ele saiu). Essa organização aparece em: 
38. O filho do vizinho contou essa história?

$\mathrm{C}$

$\mathrm{T}$

39. Vocês dois são cariocas?

$\mathrm{C}$

$\mathrm{T}$

O esquema melódico pode ser o mesmo já observado em 2.2.1. e 2.2.2.: uma seqüência de dois padrões terminais asc. 1 , sendo que o primeiro situa-se em nível mais elevado que o segundo, além de ser afetado por uma intensidade maior. Mas também encontramos no 2 GP (T) o padrão parentético. Temos nesse caso:

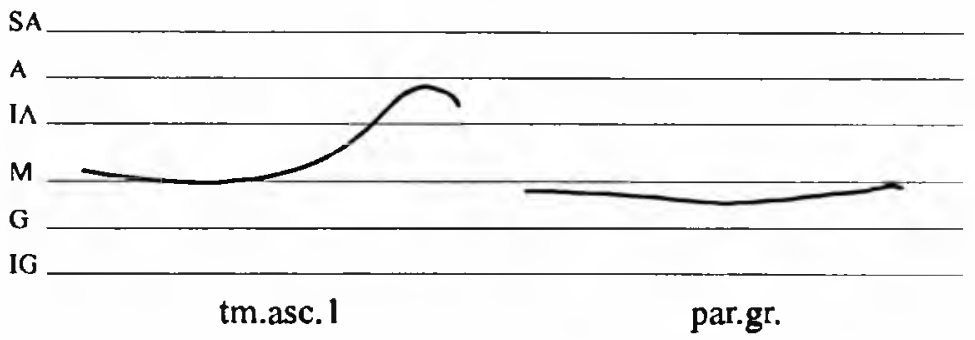

\section{Interrogativas parciais}

Nas questões parciais, a entoação também pode imprimir a estrutura C-T ao enunciado iniciado por vocábulo interrogativo. Assim, dependendo da intenção do falante expressa pela entoação, o enunciado

40. Por que você saiu ontem à noite?

pode apresentar organizações diferentes:

40.a. Por que você saiu ontem à noite? (estrutura não marcada) $\mathrm{C}$

40.b. Por que você saiu ontem à noite? (estrutura marcada pela entoação)

$\mathrm{C}$

$\mathrm{T}$

A configuração básica nesse caso é a seguinte:

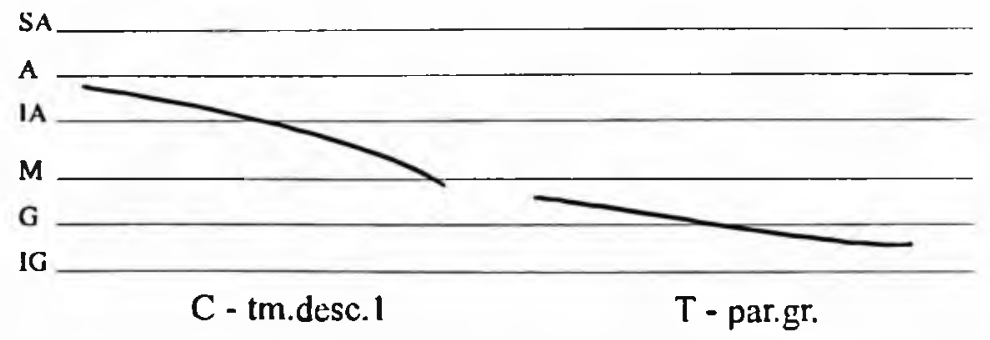


Consideremos que o GP1 é afetado por um padrão term.desc.1. Quanto ao GP2, pode ser identificado como parentético grave.

2.2.3.2. Num segundo nível de estruturação, a entoação focaliza itens lexicais que constituem o núcleo do comentário ou, mais raramente, o núcleo do tópico. Nesse caso, os elementos focalizados não formam grupos prosódicos. Não se trata, como no caso precedente, do relevo de um GP que passa a constituir o comentário, mas do relevo de um constituinte no interior do GP, constituinte que é considerado pelo locutor como o mais importante. Exemplos:

41. Você nunca veio aqui?

42. Você acha que ele teria coragem de fazer isso?

A sílaba acentuada do vocábulo focalizado tem uma elevação tonal do nível médio para o infra-agudo (ou agudo) e um aumento significativo da intensidade $e$ da duração. A presença do foco pode provocar um rebaixamento do nível do contorno entoativo final, que é freqüentemente inferior ao nível do foco. Isso pode ser observado nas duas realizações do enunciado:

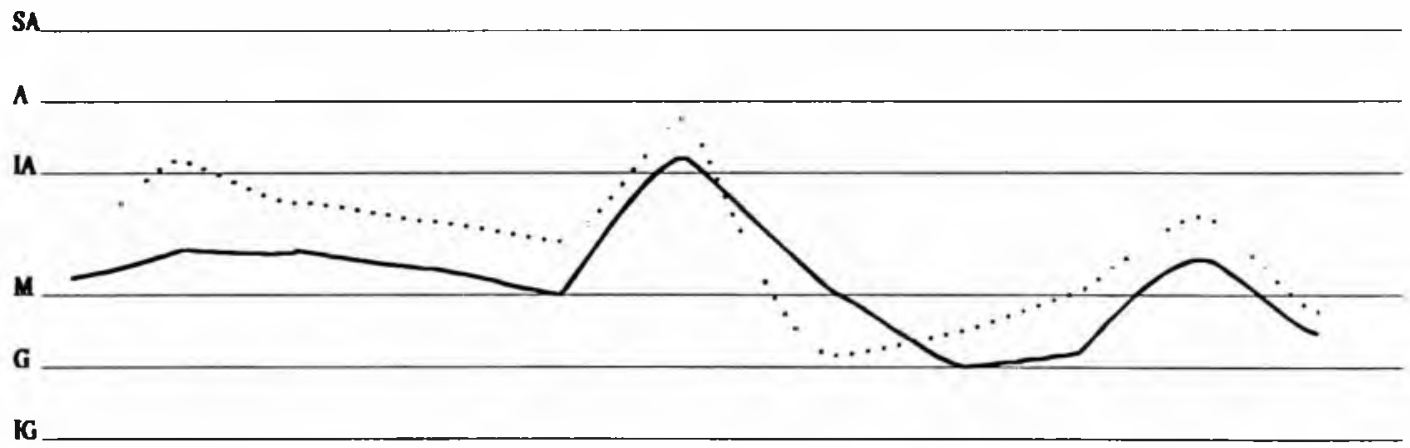

43. Você já teve muitos namorados?

Nesse caso, o contorno final do grupo mantém sua estrutura básica (padrão term.asc.1a), mas situa-se em nível mais baixo do que o normal.

O contorno entoativo do foco se assemelha, nos casos considerados, ao do padrão term.asc.1a, porém com uma participação sensivelmente menor da duração e uma participação mais constante da intensidade. Mesmo havendo deslocamento do acento tônico para a sílaba inicial do vocábulo focalizado, não se observa alteração no tipo de contorno.

É natural que o foco seja manifestado por um contorno de tipo terminal já que, constituindo o núcleo informativo do GP, ele assume (sozinho ou juntamente com o contorno final) a expressão da modalidade interrogativa. Nas questões totais examinadas, verificamos três procedimentos diferentes quando há focalização no interior do comentário: 
1) o contorno interrogativo se mantém: há nesse caso dois contornos terminais no GP:

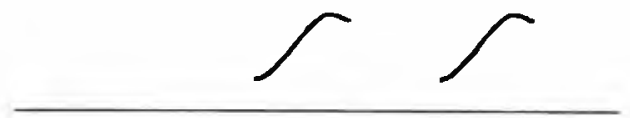

- Você já teve muitos namorados?

2) o contorno interrogativo final é atenuado. Aí a modalidade é expressa principalmente pelo contorno do foco:

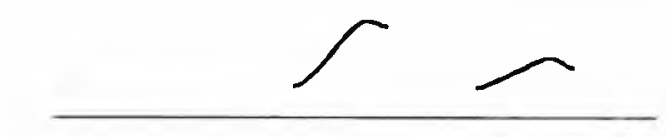

- Você já teve muitos namorados?

3) o contorno interrogativo final é completamente apagado. Nesse caso, o contorno do foco assume sozinho a expressão da modalidade:

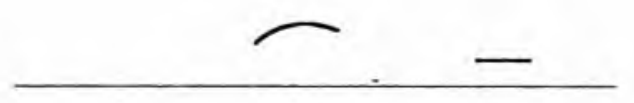

Você se sente bem aproveitado?

Quando o foco ocupa uma posição final no GP, o contorno é mais acentuado.

\section{Conclusões}

Nos enunciados interrogativos examinados, a entoação revela a estrutura em T-C dentro dos seguintes padrões:

3.1. O comentário está sempre associado a um padrão entoativo de tipo terminal que manifesta, simultaneamente, a modalidade interrogativa. Qualquer que seja a estrutura enunciativa (não marcada, marcada por alteração na ordem sintática, por extração ou apenas pela entoação) e qualquer que seja a ordem dos componentes ( $\mathrm{T}-\mathrm{C}$ ou $\mathrm{C}-\mathrm{T}$ ), o comentário é sempre afetado por um dos padrões terminais interrogativos.

3.2. Na manifestação do tópico, registramos diferentes padrões entoativos, assim distribuídos:

a) posição inicial do enunciado (estrutura T-C). Numa estrutura não marcada (na qual o tópico equivale ao sujeito gramatical), temos normalmente o padrão ct.asc. 2 ; numa estrutura marcada, em que há topicalização, observam-se os padrões ct.asc. 1 e ct.desc.1, que parecem poder alternar-se nos mesmos contextos. 
b) posição final de enunciado (estrutura marcada C-T, com ênfase no comentário). Nesse caso, temos duas configurações: o padrão term.asc.1 que reproduz, como um eco, a entoação do comentário, nas questões totais; e o padrão parentético grave, que ocorre sobretudo nas questões parciais.

3.3. Num segundo nível de estruturação enunciativa, a expressão do foco se caracteriza, nos enunciados examinados, por uma elevação sensível do nível tonal e da intensidade na sílaba acentuada do vocábulo focalizado. Nas questões totais, em vários casos, registramos alterações na estrutura acentual do vocábulo enfatizado (deslocamento do acento), bem como na configuração melódica do GP.

Esses resultados vêm confirmar o papel essencial da entoação na manifestação da estrutura enunciativa. Nesse aspecto, sua participação é sem dúvida mais efetiva do que as marcas sintáticas. Enquanto essas últimas são facultativas, as marcas entoativas são elementos constantes na hierarquização dos constituintes do enunciado.

\section{BIBLIOGRAFIA}

BOLINGER, D. (1952) Linear modification, P.M.L.A. vol. 67. 1117-1144.

CHOMSKY, N. (1970) Deep structure, surface structure and semantic interpretation, M.I.T. Press, reimpresso em: Studies on Semantic in Generative Grammar (1972), Mouton, The Hague.

DANES, F. (1960) Sentence intonation from a fonctionnal point of view, Word, 16, 34 -54

DANES, F. (1967) Order of elements and sentence intonation, in Intonation, Penguin Books, Middlesex, 1972.

DUCROT, O. (1972) Dire et ne pas dire, Hermann, Paris.

GUIMARÃES, E. (1978) Foco e pressuposição, in Foco e Pressuposição, Série Estudos 4, Uberaba.

HALLIDAY, M.A.K. (1976) Estrutura e função da linguagem, in Lyons, J. Org. Novos Horizontes em Lingüistica, Cultrix, São Paulo.

HOCHGREB, N. (1983) Análise acústico perceptiva da entoação do português: a frase interrogativa, tese de doutorado, USP.

JACKENDOFF, R.S. (1971) Semantic Interpretation in Generative Grammar, M.I.T. Press, Cambridge, Mass.

PERROT, J. (1978) Fonctions syntaxiques, énonciation, information, Bulletin de la Société Linguistique de Paris, 73, 85-101.

ROSSI, M. e DI CRISTO, A. (1980) Un modèle de détection automatique des frontières intonatives et syntaxiques, Actes des XIèmes Journées d'Etudes sur la Parole, Strasbourg, 208-238.

ZWANENBURG, W. (1965) Recherches sur la Prosodie de la Phrase Française, Universitaire Pers Leiden. 
HOCHGREB, Norma. A entoação e a organização em tópico-comentário em enunciados interrogativos. Língua e Literatura, n. 20, p. 63-79, 1992/1993.

RÉSUMÉ: Le but de ce travail est d'examiner le rôle de l' intonation dans l'expression de l'organisation en thème-propos dans des énoncés interrogatifs du portugais. Analysant des questions totales et partielles soumises préalablement à un traitement instrumental, on essaie d'identifier les patrons intonatifs de base associés à l'organisation énonciative en thème-propos et de vérifier quels sont les rapports entre ce patrons et les différentes structures syntaxiques observées. 